\title{
Flow Cytometric Analysis of Rat Striatal Nerve Terminals
}

\author{
Marina E. Wolf and Gregory Kapatos \\ Laboratory of Neurochemistry, Center for Cell Biology, Sinai Research Institute, and the Cellular and Clinical Neurobiology \\ Program, Department of Psychiatry, Wayne State University School of Medicine, Detroit, Michigan 48235
}

\begin{abstract}
Methods were developed for the analysis and isolation of striatal nerve terminals (synaptosomes) using fluorescenceactivated cell sorting (FACS). Comparison of the light-scattering properties of synaptosomal and mitochondrial fractions indicated that particles in the synaptosomal fraction were generally larger and more sensitive to hypotonic lysis, consistent with results obtained by other methods of analysis. FACS analysis using indirect immunofluorescence techniques indicated that approximately $84 \%$ of the synaptosomal fraction was labeled by monoclonal antibody (mAb) A2B5 and thus appeared to be of neuronal origin. After permeabilization, between 5 and $10 \%$ of the particles were labeled by a mAb to glial fibrillary acidic protein, suggesting that they were derived from astrocytes. A fluorescent voltage-sensitive dye (VSD) was used to distinguish intact synaptosomes from free mitochondria (only the former maintain a membrane potential under the present experimental conditions). Approximately $83 \%$ of the synaptosomal fraction exhibited increased fluorescence after incubation with the VSD; furthermore, the fluorescence signal decreased in response to depolarizing agents (elevated potassium and veratridine). A portion of the mitochondrial fraction responded similarly, consistent with the presence of contaminating synaptosomes. Analysis of synaptosomal labeling by 11 fluorescein-conjugated plant lectins indicated that striatal nerve terminals differ significantly in their cell surface glycoconjugates. Subpopulations of synaptosomes defined on the basis of lectin binding were collected by FACS onto filters and probed with a mAb to tyrosine hydroxylase (TH) using Western blot techniques. While subpopulations exhibited different amounts of TH immunoreactivity, none of the lectins appeared to recognize TH-positive (i.e., dopaminergic) synaptosomes exclusively. These findings demonstrate that synaptosomes can be characterized and isolated for further study based on FACS analysis of properties such as size, membrane potential, and the presence of intracellular or cell surface molecules.
\end{abstract}

Most tissue preparations currently available for studying neuronal function consist of an indeterminate number of cell types. This cellular complexity limits the extent to which the properties

Received Nov. 9, 1987; revised Apr. 1 1, 1988; accepted June 2, 1988

We thank Tim Geddes and Vicki Kemski for excellent technical assistance, and Drs. James G. Granneman, Louis A. Chiodo, Michael J. Bannon, and Matthew P. Galloway for helpful discussions of the manuscript. We also thank Cynthia Stinson and Kate Early for expert assistance with manuscript preparation. This work was supported in part by U.S. Public Health Service Grant MH-43657. M. W. is the recipient of a National Research Service Award (NS-08413).

Correspondence should be addressed to Dr. Marina E. Wolf, Laboratory of Neurochemistry, Center for Cell Biology, Sinai Research Institute, 6767 West Outer Drive, Detroit, MI 48235

Copyright (c) 1989 Society for Neuroscience $0270-6474 / 89 / 010094-12 \$ 02.00 / 0$ of a particular type of neuron can be examined. Flow cytometry enables simultaneous measurements of several parameters to be made on a cell-by-cell basis for many thousands of cells in a population. These parameters may include size, internal structure and granularity, and the presence of cell surface molecules which can be labeled with fluorescent probes. Subpopulations of cells can then be separated by fluorescence-activated cell sorting (FACS). To date, flow cytometric methods have been applied mainly to studies of the immune system (Ledbetter and Herzenberg, 1979; Loken and Stall, 1982). Recently, however, a number of neuronal populations have been successfully isolated from dissociated tissue by FACS and maintained in primary culture for subsequent characterization (Moskal and Schaffner, 1986; O'Brien and Fischbach, 1986; di Porzio et al., 1987; Schaffner et al., 1987).

In addition to whole cells, flow cytometry can be used to study any subcellular element that can be prepared in a single particle suspension, including free mitochondria, whole nuclei, and chromosomes (see Kruth, 1982, for a review), as well as membrane vesicle fractions (Moktari et al., 1986). We have developed flow cytometric techniques for the analysis of resealed nerve terminals (synaptosomes). The present results demonstrate that, when analyzed by flow cytometry, intact synaptosomes prepared from rat striatum can be characterized based on size, membrane potential, and cell surface molecules, and thereby distinguished from other particles in the synaptosomal fraction (e.g., free mitochondria or particles containing astrocyte-specific markers). Subpopulations of synaptosomes defined by any of the above parameters can be isolated by FACS and subsequently probed for antigens of interest, such as tyrosine hydroxylase (TH), using Western blot techniques. The accompanying paper (Wolf and Kapatos, 1989) demonstrates that synaptosomes that have been permeabilized by fixation can be isolated by FACS based on the presence of intracellular antigens and that this strategy can be used to obtain greatly enriched preparations of dopaminergic striatal synaptosomes.

\section{Materials and Methods}

Preparation of synaptosomes. Male Sprague-Dawley rats (200-300 gm) obtained from Hilltop Laboratories (Portage, MI) were used in all experiments. Rats were killed by decapitation and the striata dissected over ice. Synaptosomes were prepared according to a modification of the method of Gray and Whittaker (1962). All sucrose solutions were buffered with $10 \mathrm{~mm}$ HEPES to $\mathrm{pH} 7.4$ and contained $1 \mathrm{~mm}$ EDTA. Striata were placed in $30 \mathrm{vol}$ of an ice-cold solution of $0.32 \mathrm{M}$ sucrose and homogenized using a glass homogenizer and a Teflon pestle. Tissue was first suspended by hand, then homogenized at $800 \mathrm{rpm}$ with 10 slow passes of the pestle. The homogenate was centrifuged at $1000 \times$ $g$ for $10 \mathrm{~min}$. The supernatant was removed with a Pasteur pipet and centrifuged at $16,000 \times g$ for $15 \mathrm{~min}$. The resulting pellet was resuspended in $30 \mathrm{vol}$ of $0.32 \mathrm{M}$ sucrose by homogenization as described above. This homogenate was was gently layered onto discontinuous 
sucrose gradients consisting of $4.3 \mathrm{ml}$ of $1.2 \mathrm{M}$ sucrosc, $4.3 \mathrm{ml}$ of $0.8 \mathrm{M}$ sucrose, and $1 \mathrm{ml}$ of $0.32 \mathrm{M}$ sucrose. One gradient was used for the homogenate obtained from the striata of one rat. The gradients were centrifuged at $63,000 \times g$ for $90 \mathrm{~min}$ using a SW40Ti rotor (Beckman). Synaptosomes were harvested from the $0.8 / 1.2 \mathrm{M}$ sucrose interface with a Pasteur pipet, gradually diluted over $30 \mathrm{~min}$ with $0.32 \mathrm{M}$ sucrose, resuspended by homogenization, and centrifuged at $16,000 \times g$ for 15 $\mathrm{min}$. The synaptosomal pellet obtained from each gradient was resuspended in $1 \mathrm{ml}$ of Kreb's Ringer phosphate (KRP) buffer consisting of $121.9 \mathrm{~mm} \mathrm{NaCl}, 0.87 \mathrm{mM} \mathrm{CaCl}_{2}, 4.89 \mathrm{~mm} \mathrm{KCl}, 1.23 \mathrm{~mm} \mathrm{MgSO}_{4}, 1.23$

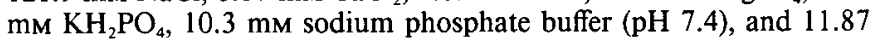
$\mathrm{mm}$ glucose. This suspension contained approximately $1 \mathrm{mg}$ synaptosomal protein $/ \mathrm{ml}$. Synaptosomes were used at this concentration for incubations and labeling, and were diluted 1:100 for analysis by FACS. Where indicated, freshly prepared synaptosomes were permeabilized with modified Zamboni fixative prior to use (see Wolf and Kapatos, 1989). For experiments utilizing free mitochondria, the mitochondrial pellet obtained from a sucrose gradient was surface-washed 3 times and resuspended in $500 \mu \mathrm{l}$ of KRP buffer. Protein concentration was determined by the method of Peterson (1977).

Flow cytometric analysis and sorting. Flow cytometry was performed on a FACS 440 (Becton-Dickinson, Mountain View, CA) using a $5 \mathrm{~W}$ argon-ion laser (Spectra Physics) tuned to generate $200 \mathrm{~mW}$ with a 488 $\mathrm{nm}$ emission line. This system is capable of detecting 4 parameters simultaneously, including forward angle light scatter, $90^{\circ}$ light scatter and 2 colors of fluorescence. Photomultipliers were operated at $400 \mathrm{~V}$ $\left(90^{\circ}\right.$ scatter) and $600 \mathrm{~V}$ (fluorescence 1 and 2). A neutral density filter (ND1) was used in the detection of forward angle light scatter. Fluorescein, which is excited at $488 \mathrm{~nm}$, was used as the chromophore in all studies. Fluorescence emissions were passed through a $530 / 30 \mathrm{~nm}$ bandpass filter (all optics provided by Becton-Dickinson). Prior to each run, the cell stream was aligned to optimize signals using glutaraldehydefixed autofluorescent chick red blood cells (Sigma Chemical Co., St. Louis) and polystyrene microspheres (Polysciences, Inc., Warrington, PA) as standards. Synaptosomal fluorescence was analyzed with logarithmic amplifiers set for either 4 or $5 \log$ decades (see figure legends). A $50 \mu \mathrm{m}$ nozzle was used in all experiments. Sheath fluid consisted of $0.9 \% \mathrm{NaCl}$. Analysis and sorting were performed at a sample flow rate of approximately 2000 events/sec. The head drive frequency during sorting was approximately $37,500 \mathrm{~Hz}$. The sort purity under these conditions was between 85 and $95 \%$. Analysis was based on 20,000 events/ sample. List mode data were stored using a PDP 11/23-based computer (Consort 40; Becton-Dickinson).

Detection of membrane potential. 3,3-Dipentyloxacarbocyanine [Di$\mathrm{O}-\mathrm{C}_{5}(3)$; Molecular Probes, Eugene, OR] was used in all voltage-sensitive dye experiments. Care was taken to keep the dye protected from light and air. A stock solution of $10^{-4} \mathrm{M} \mathrm{Di-O}-\mathrm{C}_{5}(3)$ in ethanol was diluted $1: 100$ in distilled water. Five microliters of this stock were added to synaptosomes that had been diluted 1:100 with KRP buffer (500 $\mu \mathrm{l}$ total volume) to achieve a final $\mathrm{Di}-\mathrm{O}-\mathrm{C}_{5}(3)$ concentration of $10^{-8} \mathrm{M}$. In all cases, acquisition of 20,000 events for FACS analysis was begun 2 min after addition of the dye. In some experiments, synaptosomes were incubated with depolarizing agents (veratridine or elevated potassium) for $2 \mathrm{~min}$ prior to the addition of dye. Veratridine (Sigma) was dissolved in dimethylsulfoxide (DMSO) and diluted 1:100 to achieve a final concentration of $75 \mu \mathrm{M}$ in the synaptosomal sample. Addition of DMSO alone had no effect on synaptosomal mcmbranc potential. When elevated potassium was used as a depolarizing agent, synaptosomes were diluted 1:100 into modified KRP buffer containing $55 \mathrm{mM} \mathrm{KCl}$ and incubated for $2 \mathrm{~min}$ before addition of dye. The $\mathrm{NaCl}$ concentration in this buffer was reduced accordingly in order to maintain isotonicity.

Labeling of synaptosomes using antibodies or lectins. Freshly prepared synaptosomes or synaptosomes that had been permeabilized with modified Zamboni fluid (see Wolf and Kapatos, 1989) were incubated for $1 \mathrm{hr}$ at $4^{\circ} \mathrm{C}$ in KRP buffer (pH 7.4) containing $2 \%$ normal goat serum (NGS; Gibco Laboratories, Grand Island, NY) to saturate nonspecific antibody binding sites. Synaptosomes were then incubated overnight at $4^{\circ} \mathrm{C}$ with primary antibody. After washing 3 times by centrifugation at $16,000 \times g(15 \mathrm{~min})$ followed by resuspension in KRP buffer plus $2 \%$ NGS, synaptosomes were reacted with a 1:50 dilution of the appropriate fluorescein isothiocyanatc-conjugated (FITC) $\mathrm{F}(\mathrm{ab})_{2}$ goat secondary antibody (Jackson ImmunoResearch, Avondale, PA) and incubated for 1 $\mathrm{hr}$ at $4^{\circ} \mathrm{C}$. Synaptosomes were washed 3 times and resuspended in KRP buffer prior to FACS analysis. Specific antibody labeling was defined as total labeling with the monoclonal antibody of interest minus nonspe- cific labeling observed with control ascites fluid containing mouse Ig of the same class. Control ascites was obtained from either of 2 adjuvantinduced tumor lines: MOPC21 $\left(\operatorname{IgG}_{1}\right)$ and MOPC104E $\left(\operatorname{IgM}_{1}\right)$. For all antibodies, preliminary experiments were conducted to compare specific labeling at 3 or more dilutions. The dilution yielding the maximal specific labeling was used in all subsequent experiments. FITC-conjugated plant lectins were obtained from Vector Laboratories (Burlingame, CA). Lectins were incubated with synaptosomes in KRP buffer $(\mathrm{pH} 7.4)$ for $30 \mathrm{~min}$ at $4^{\circ} \mathrm{C}$ at a final lectin concentration of $2 \mu \mathrm{g} / \mathrm{ml}$. After centrifugation at $16,000 \times g$ for $15 \mathrm{~min}$, all of the supernatant was removed. The synaptosomes were washed once and resuspended in KRP buffer prior to FACS analysis.

Western analysis of sorted synaptosomes. TH was detected using LNC 1 , a monoclonal antibody raised against $\mathrm{TH}$ purified from the $\mathrm{PC} 12$ pheochromocytoma cell line (G. Kapatos and D. Kuhn, in prcparation). Synaptosomes were sorted based on fluorescence or light scatter and collected onto HA-type membrane filters $(0.45 \mu \mathrm{m}$ pore size; Millipore, Bedford, MA) under vacuum. Synaptosomes collected in this manner accumulate on the filters in discrete spots which can be detected using an ultraviolet source. These "spot-blots" were fixed by incubation for $15 \mathrm{~min}$ in $10 \% \mathrm{vol} / \mathrm{vol}$ acetic acid and $25 \% \mathrm{vol} / \mathrm{vol}$ isopropyl alcohol (Jahn et al., 1984), incubated in 5\% nonfat dry milk to block nonspecific antibody binding sites (Johnson et al., 1984), and then reacted with 0.2 $\mu \mathrm{g} / \mathrm{ml}$ of $\mathrm{LNC} 1 \mathrm{IgG}$. The antigen-antibody complex was visualized enzymatically with goat anti-mouse immunoglobulin conjugated to alkaline phosphatase (Blake et al., 1984). Relative amounts of TH in spotblots were quantified using a Zeineh soft laser scanning densitometer and accompanying software (Biomed Instruments, Fullerton, CA).

\section{Results}

Light scatter analysis of striatal synaptosomes

Initial flow cytometric analysis of the synaptosomal fraction was bascd on measurements of forward angle and $90^{\circ}$ light scatter. Briefly, forward angle light scatter (FALS) is a measure of light scattered at narrow angles and is proportional to particle size (Mullaney et al., 1969). The amount of light scattered at wider angles is influenced by factors such as secretory granule content, nuclear diameter, and the size and shape of intracellular organelles (Kerker et al., 1979; Benson et al., 1984; Hatfield and Hymer, $1986 \mathrm{a}, \mathrm{b})$. The $90^{\circ}$ light scatter signal therefore serves as a relative indicator of fine internal structure.

The light scattering properties of the synaptosomal fraction, the mitochondrial fraction, and polystyrene microspheres of known diameter are compared in Figure 1. These data suggest that particles in the synaptosomal and mitochondrial fractions have diameters ranging from several tenths of a micron to several microns, and that synaptosomes are generally larger. This is consistent with previous electron microscopic studies, in which most synaptosomes were observed to be between 0.5 and $1 \mu \mathrm{m}$ in diameter, while free mitochondria were usually $0.5 \mu \mathrm{m}$ or less (Gray and Whittaker, 1962; Dunkley et al., 1986).

Resuspension of the synaptosomal fraction in water followed by repeated freeze/thaw cycles disrupted the synaptosomal scatter pattern, generating a pattern similar to that of the mitochondrial fraction (Fig. 2). Particles with FALS as low as 8 appear to have been lysed, suggesting that some of the smaller particles in the synaptosomal fraction may represent intact synaptosomes. Identical treatment of the mitochondrial fraction did not significantly alter its light scattering properties (data not shown), consistent with previous reports that mitochondrial morphology is fairly well preserved after hypotonic shock (Jones and Matus, 1974; Haas et al., 1988).

\section{Detection of neuron- and astrocyte-derived particles}

Monoclonal antibodies directed against neuron-specific and astrocyte-specific markers were used to further characterize the 
0.7 AND 1.4 MICRON BEADS

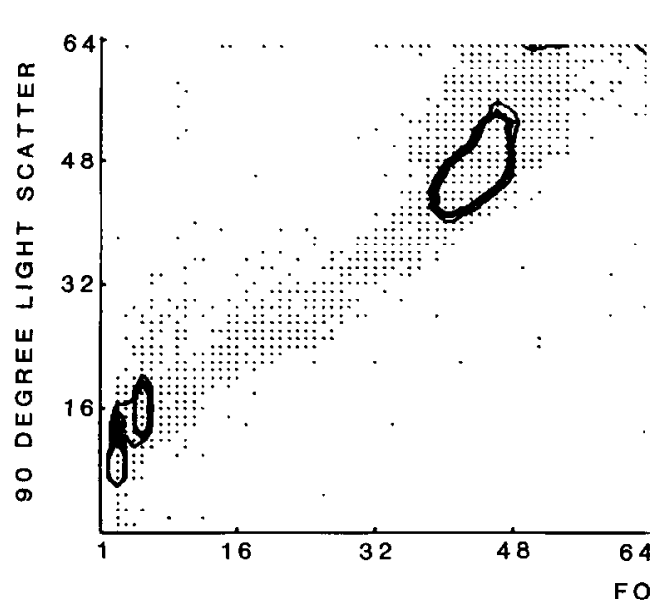

STRIATAL SYNAPTOSOMES

AND 1.4 MICRON BEADS

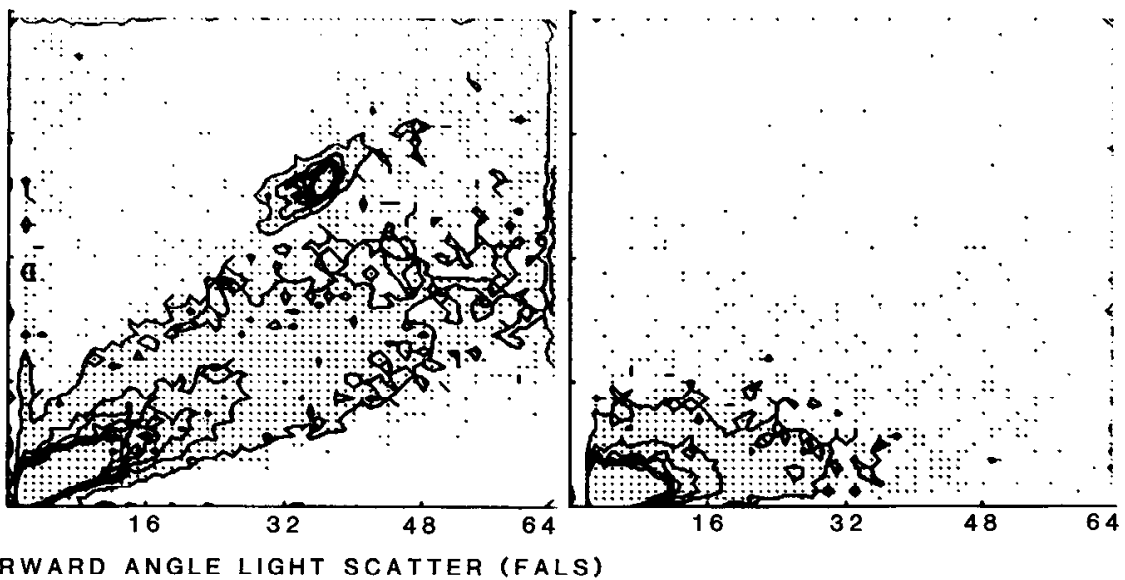

Figure 1. Dual parameter contour plots comparing the light scattering properties of polystyrene microspheres, the synaptosomal fraction, and a mitochondria-enriched fraction prepared from rat striatum. In all cases, analysis was based on 20,000 particles. For each particle, FALS and $90^{\circ}$ scatter are presented as $x$ and $y$ coordinates, respectively, on a $64 \times 64$ grid. These units (1-64) are arbitrary and intended to convey relative differences in light scatter. The relative number of particles at a given location on the grid is indicated by contour lines. All samples were analyzed with identical instrument settings, cnabling the range of synaptosomal and mitochondrial sizes to be estimated by comparing their FALS signals to those generated by microspheres of known diameter.

origin of particles in the synaptosomal fraction. Antibody binding was assessed using indirect immunofluorescence techniques in combination with FACS. Since some of these markers are intracellular, these studies were performed using striatal synaptosomes that had been permeabilized by fixation with modified Zamboni fluid as described in the accompanying paper (Wolf and Kapatos, 1989). Specific antibody labeling was defined as total labeling with the monoclonal antibody of interest minus nonspecific labeling observed with a control monoclonal antibody of the same Ig class (see Materials and Methods). Results are expressed as the mean of 3 labeling experiments performed with different synaptosomal preparations.

Monoclonal antibody A2B5, which has been shown to bind to most or all neurons in the mammalian CNS (Eisenbarth et al., 1979), labeled $83.9 \pm 1.7 \%$ of the synaptosomal fraction (Fig. 3). An identical percentage of events was labeled by A2B5 in experiments using fresh, nonpermeabilized synaptosomes (data not shown). A2B5-labeled particles were found along the entire range of FALS signals. This indicates that some of the smallest particles in the synaptosomal fraction, as well as the larger particles, are of neuronal origin. Neurofilament was used as a second neuronal marker. Monoclonal NF1 neurofilament antibodies (Labsystems, Finland), which detect the 200,000 Da neurofilament polypeptide, specifically labeled approximately $50 \%$ of the synaptosomal fraction (Fig. 3). This is probably an underestimate of the actual percentage of neurofilament-containing particles, however, since there was considerable overlap between the populations labeled by neurofilament and by its control monoclonal antibody MOPC21.

It is possible that pinched-off glial cell fragments (gliosomes) are formed during the preparation of synaptosomes and that these particles band with the synaptosomal fraction during density gradient centrifugation (Cotman et al., 1971; Henn et al., 1976). Glial fibrillary acidic protein (GFAP), the main subunit protein comprising intermediate filaments of astrocytes, was used as an astrocyte-specific marker (Bignami et al., 1980). FACS
Figure 2. Effect of resuspension in distilled water and repeated freeze/thaw cycles on light scattering properties of the synaptosomal fraction.
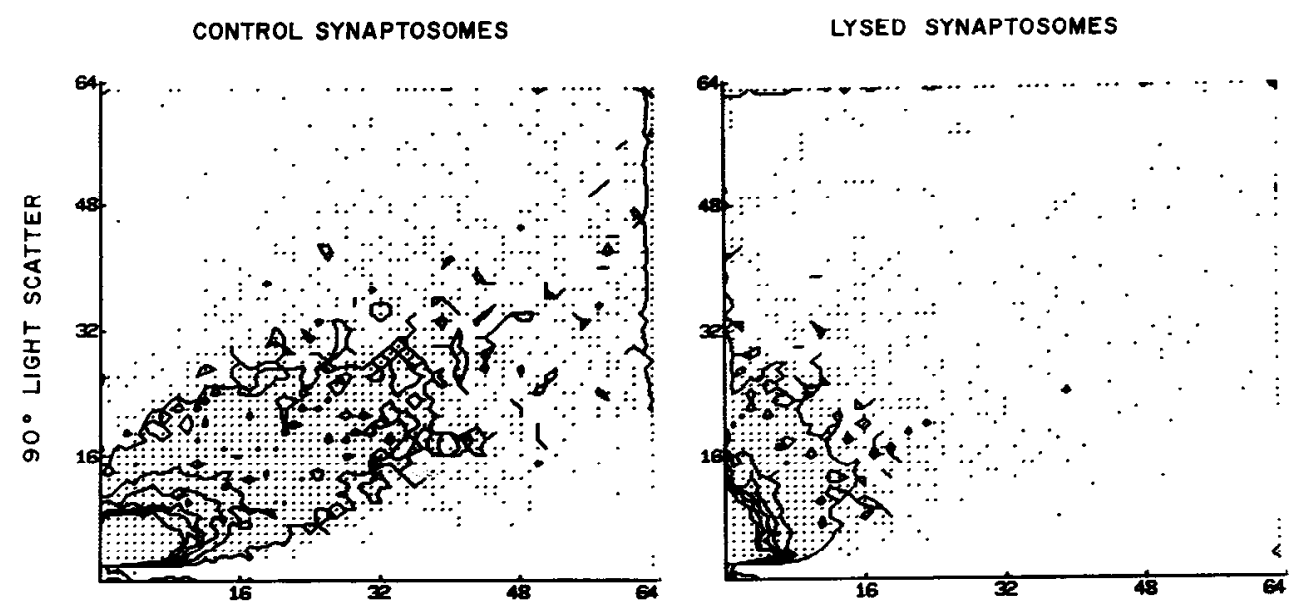

FORWARD ANGLE LIGHT SCATTER 

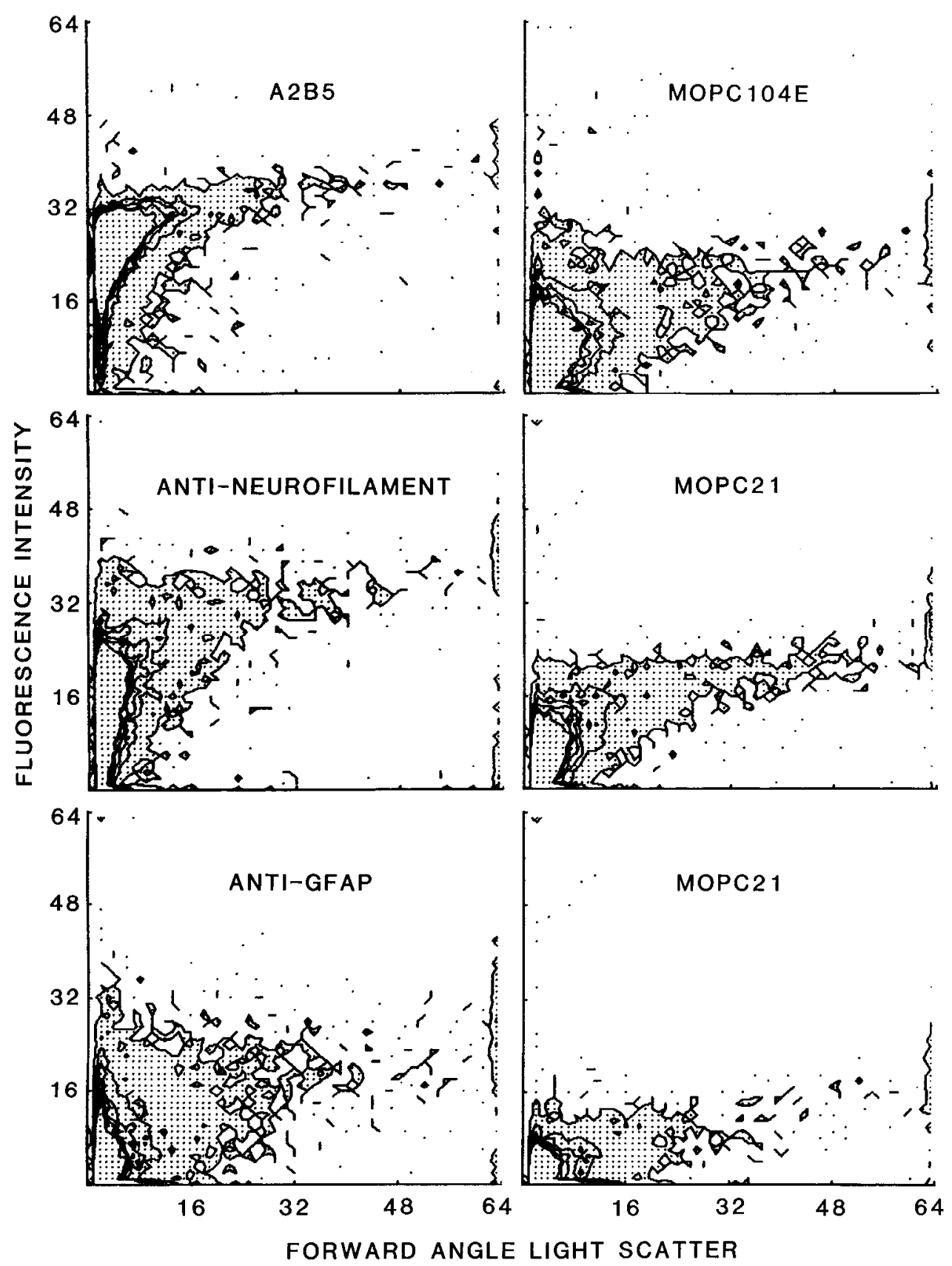

Figure 3. Specific labeling of the synaptosomal fraction by monoclonal antibody A2B5 (1:100), monoclonal NF1 neurofilament antibody $(1: 100)$, antiGFAP monoclonal antibody $(1: 1000)$, and equivalent dilutions of their appropriate control antibodies (MOPC104E, MOPC21, and MOPC21, respectively). Synaptosomes were incubated with the dilution of primary antibody indicated in parentheses followed by FITC secondary antibody. A $4 \log$ unit range of fluorescence intensity is presented on the abscissa. analysis demonstrated that anti-GFAP monoclonal antibodies (Labsystems, Finland) labeled $7.5 \pm 1.4 \%$ of the synaptosomal fraction, suggesting the presence of astrocyte-derived particles (Fig. 3). The rangc of FALS signals generated by GFAP-labeled particles indicates that gliosomes have approximately the same range of sizes as synaptosomes.

\section{Detection of particles possessing a membrane potential}

It has been shown previously that intact synaptosomes maintain a significant membrane potential in medium similar to that used in the present studies (Blaustein and Goldring, 1975; Deutsch and Rafalowska, 1979; Hansson et al., 1980; Scott and Nicholls, 1980; Heinonen et al., 1985), while free mitochondria do not (see Discussion). This difference was used as an alternative basis for identifying intact synaptosomes and distinguishing them from free mitochondria and other particles.
Membrane potential can be measured with flow cytometric methods using fluorescent voltage-sensitive dyes (Shapiro et al., 1979; Seligman et al., 1981; Seligman and Gallin, 1983; Hickman et al., 1984; Tatham et al., 1984; Wilson and Chused, 1985; Jenssen et al., 1986; Lazzari et al., 1986; Sullivan et al., 1987; Mandler et al., 1988). The present studies utilized Di-O-C $\mathrm{C}_{5}(3)$, a cationic dye that accumulates in the negatively charged interior of cells or synaptosomes. The amount of Di-O-C $\mathrm{C}_{5}(3)$ that enters a synaptosome, as determined by fluorescence intensity, therefore provides an index of the extent to which the synaptosome is hyperpolarized with respect to the external medium (for reviews, see Cohen and Salzberg, 1978; Waggoner, 1979; Bashford, 1981).

The results of adding Di-O-C $\mathrm{C}_{5}(3)$ to the synaptosomal and mitochondrial fractions $2 \mathrm{~min}$ prior to FACS analysis are illustrated by dual parameter plots of FALS and fluorescence (Fig. 


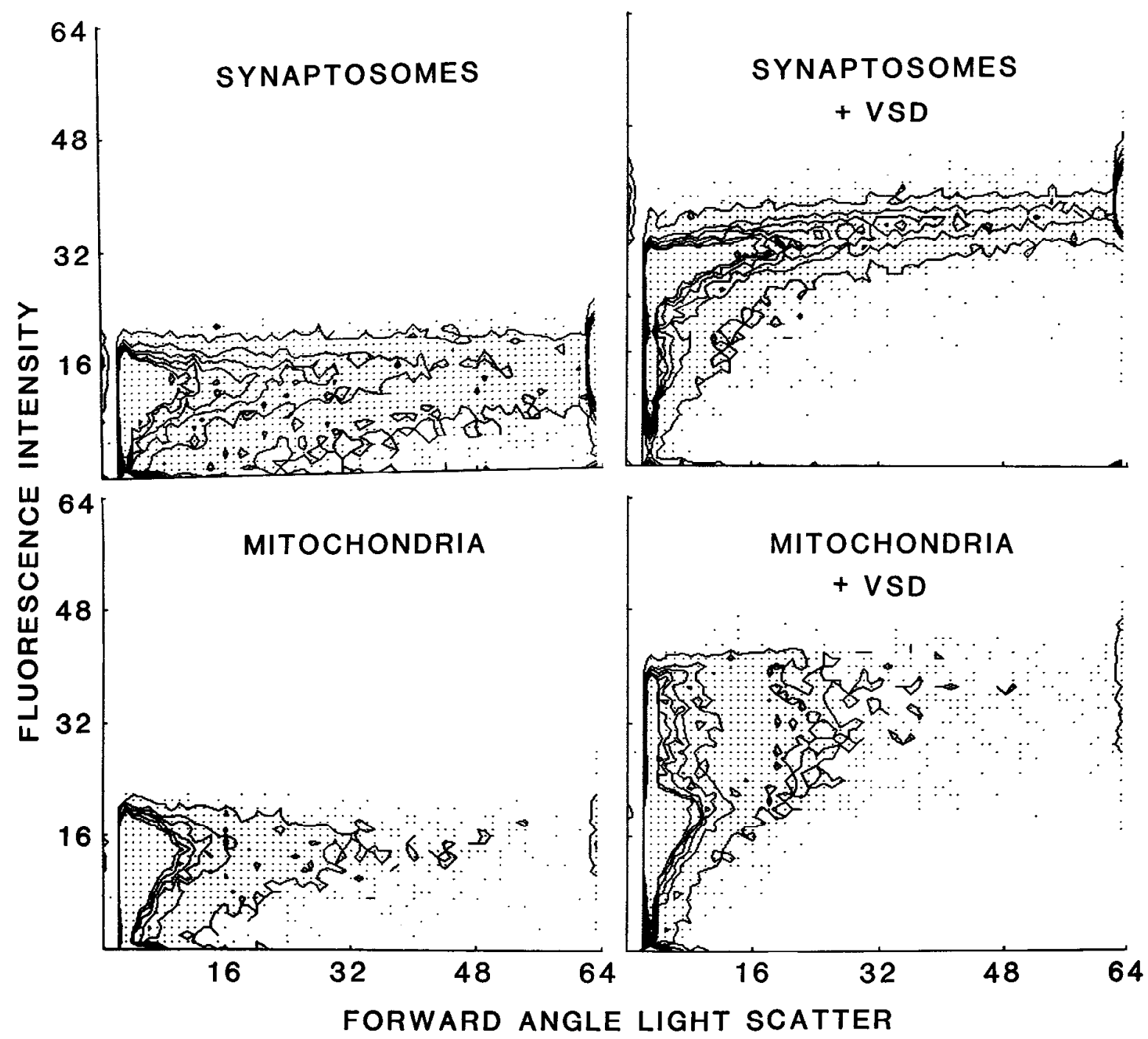

Figure 4. Analysis of the fluorescence intensity of the synaptosomal and mitochondrial fractions before and after addition of the voltage-sensitive dye (VSD) Di-O-C $\mathrm{C}_{5}(3)$. A 5 log unit range of fluorescence intensity is presented on the abscissa.

4). Fluorescence of the synaptosomal fraction increased dramatically following incubation with $\mathrm{Di}-\mathrm{O}-\mathrm{C}_{5}(3)$, indicating that most of the particles in the synaptosomal fraction have a significant membrane potential. In contrast, the majority of particles in the mitochondrial fraction exhibited only small increases in fluorescence.

Dual parameter plots such as those in Figure 4 offer the advantage of preserving information about the relationship between fluorescence intensity and other parameters (e.g., FALS) for each particle. For example, Figure 4 shows that it is the smaller particles in both the synaptosomal and mitochondrial fractions that lack a membrane potential. This is consistent with the presence of contaminating mitochondria in the synaptosomal fraction. Conversely, the larger particles in the mitochondrial fraction which possess a membrane potential probably represent contaminating synaptosomes (see below).

Certain types of analysis can be accomplished more readily, however, if the data are presented as single parameter histograms depicting the fluorescence distribution profile for the population. In the histograms shown in Figure 5, fluorescence is plotted on a log scale and expressed as channel number (0-255), a relative measure of fluorescence intensity. It is helpful to note that, while fluorescence is measured over 256 channels in all cxpcriments, fluorescence data are collapsed to 64 units when data are presented in the dual parameter mode (e.g., Fig. 4). Thus, the same range of fluorescence intensity ( $5 \log$ units) is represented in both single and dual parameter plots, even though the scale values are different. A change of approximately 51 channels in the single parameter mode or 13 units in the dual parameter mode both indicate a 10 -fold difference in fluorescence.

Changes in relative fluorescence intensity can be quantified by calculating the mean channel number $(\mathrm{MN})$, or average relative fluorescence, for synaptosomes and mitochondria in different treatment groups. While a unimodal distribution of native fluorescence was found for a control synaptosomal fraction (Fig. $5 A ; \mathrm{MN}=48$ ), a bimodal fluorescence distribution profile was observed after incubation with Di-O-C $\mathrm{C}_{5}$ (3) (Fig. 5B). Most of the particles exhibited large increases in fluorescence $(\mathrm{MN}=$ 128 ), while the remainder exhibited only very slight increases 
$(\mathrm{MN}=54)$. Analysis of 4 different synaptosomal preparations indicated that $82.6 \pm 1.2 \%$ of the particles in the synaptosomal fraction responded to dye addition with large increases in fluorescence, indicating that they possess a significant membrane potential. It seems likely that these particles represent intact synaptosomes (or astrocyte-derived particles; see below).

Additional experiments showed that the synaptosomal membrane potential is sensitive to depolarizing agents (Fig. 5, $C$, $D$ ). Synaptosomes transferred to medium containing $55 \mathrm{~mm}$ potassium chloride or $75 \mu \mathrm{M}$ veratridine just before the addition of Di-O- $\mathrm{C}_{5}(3)$ exhibited a leftward shift in fluorescence intensity compared with synaptosomes incubated with $\mathrm{Di}-\mathrm{O}-\mathrm{C}_{5}(3)$ alone. This suggests that they were depolarized by these treatments and therefore took up less of the fluorescent voltage-sensitive dye. Depolarization-induced changes in relative fluorescence were quantified in terms of $\mathrm{MN}$ for the subpopulation of events in the synaptosomal fraction that responded to addition of $\mathrm{Di}$ $\mathrm{O}-\mathrm{C}_{5}(3)$ with a large increase in fluorescence. $\mathrm{MN}$ values were as follows: dye only, 128 (Fig. $5 B$ ); 55 mм potassium chloride, 115 (Fig. 5C); $75 \mu \mathrm{M}$ veratridine, 118 (Fig. 5D). A decrease in MN from 128 to 118 represents approximately a $37.5 \%$ decrease in fluorescence intensity.

The response of the mitochondrial fraction to incubation with Di-O- $\mathrm{C}_{5}(3)$ under control and depolarizing conditions is presented in the right half of Figure 5. Like the synaptosomal fraction, the mitochondrial fraction switched from a unimodal (MN $=46$; Fig. $5 E$ ) to a bimodal $(\mathrm{MN}=63$ and 134 ; Fig. $5 F)$ fluorescence distribution after dye addition. The subpopulation exhibiting little or no increase in fluorescence intensity presumably contained free mitochondria, damaged synaptosomes, and membrane fragments. The small shift in MN exhibited by this subpopulation may suggest that some free mitochondria are slightly hyperpolarized. The subpopulation exhibiting a large increase in fluorescence intensity (approximately $30 \%$ of total) presumably consists of contaminating synaptosomes, since this subpopulation and the majority of particles in the synaptosomal fraction have similar MNs and, therefore, similar membrane potentials. This is supported by the observation that this component of the mitochondrial fraction also exhibited a leftward shift in fluorescence intensity, suggestive of depolarization, in response to elevated potassium or veratridine (Fig. 5, $G, H$ ). Mitochondria lack voltage-dependent sodium channcls and would therefore not be expected to respond to veratridine.

\section{Recognition of synaptosomes by plant lectins}

The binding of 11 FITC-conjugated plant lectins to intact striatal synaptosomes was analyzed by FACS. There were substantial differences in the percentages of synaptosomes labeled by lectins with different carbohydrate binding specificities, suggesting that subpopulations of nerve terminals differ in their cell surface glycoconjugates (Table 1). In addition, differences in the pattern of synaptosomal labeling were observed, as illustrated by dual parameter plots of FALS and fluorescence for 3 representative lectins (Fig. 6). Since the fluorescence intensity of a single synaptosome is proportional to the number of lectin molecules bound and therefore proportional to the number of lectin receptors on the synaptosome, these plots can yield information about the relative numbcr of lectin receptors per terminal.

For Phaseolus vulgaris leucoagglutinin (PHA-L), labeled synaptosomes appeared as a tight band of approximately constant fluorescence intensity. This suggests that synaptosomes are fairly

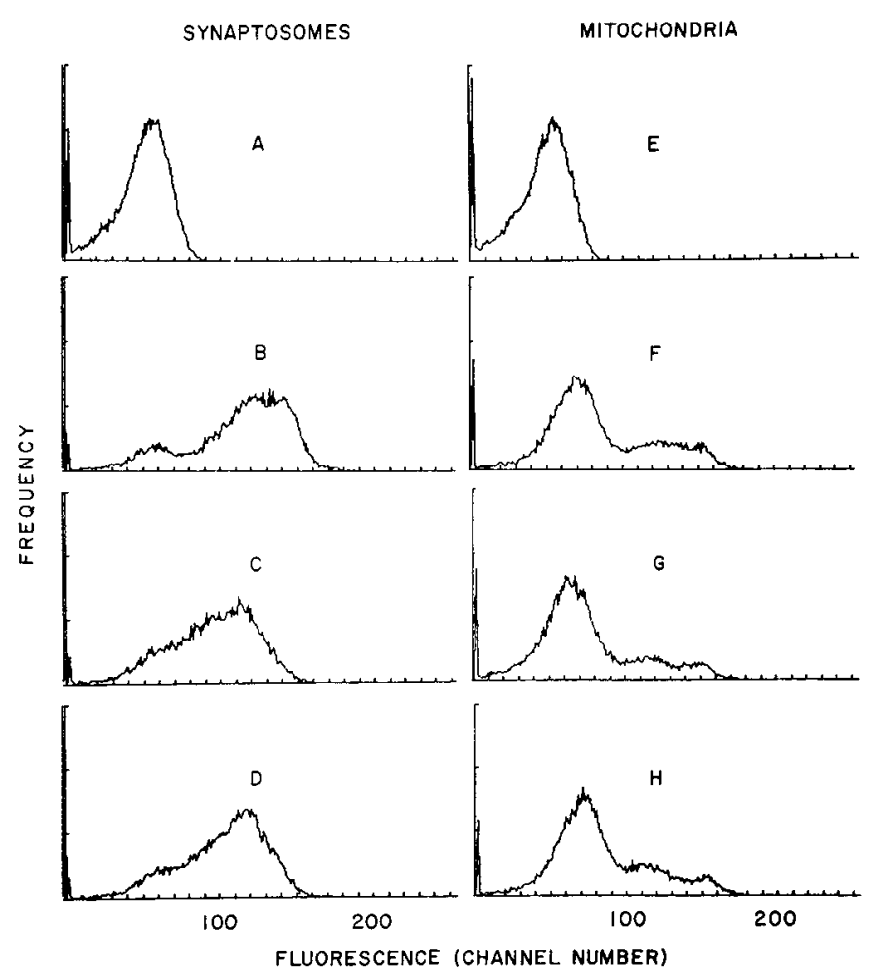

Figure 5. Single parameter histograms illustrating the effect of $\mathrm{Di}$ $-\mathrm{O}-\mathrm{C}_{5}(3)$ on the fluorescence of the synaptosomal fraction (left panels) and mitochondrial fraction (right panels) under control and depolarizing conditions. $A$, Control synaptosomes; $B$, synaptosomes, dye only; $C$, synaptosomes, $55 \mathrm{~mm} \mathrm{KCl}$ and dye; $D$, synaptosomes, $75 \mu \mathrm{M}$ veratridine and dye; $E$, control mitochondria; $F$, mitochondria, dye only; $G$, mitochondria, $55 \mathrm{~mm} \mathrm{KCl}$ and dye; $H$, mitochondria, $75 \mu \mathrm{M}$ veratridine and dye. Depolarizing conditions result in a leftward shift in fluorescence intensity for the synaptosomal fraction and for the portion of the mitochondrial fraction with a significant membrane potential (channels 100-170). Fluorescence was analyzed over 256 channels, representing a $5 \log$ unit range of fluorescence intensity.

homogeneous with respect to the number of PHA-L binding sites. Fluorescence appears to increase slightly with increasing FALS, but this is not surprising since larger synaptosomes would be expected to have a greater surface area and, therefore, more lectin binding sites. In contrast, a much broader range of fluorescence intensities was observed for synaptosomes labeled by soybean agglutinin (SA). This suggests that synaptosomes that produce the same FALS signal, and are therefore similar in size, can differ significantly in the number of their SA binding sites.

\section{Analysis of TH in synaptosomal subpopulations defined by lectin binding}

FACS-isolated synaptosomes can be further characterized using Western blot techniques. This is illustrated by a series of experiments in which subpopulations of synaptosomes separated on the basis of lectin binding were compared with respect to their content of TH, the rate-limiting enzyme in dopamine (DA) biosynthesis. Approximately $16 \%$ of striatal nerve terminals are thought to be dopaminergic (Hökfelt, 1968; Hökfelt and Ungerstedt, 1969; Iversen and Schon, 1973) and would therefore be expected to contain $\mathrm{TH}$.

Preliminary experiments demonstrated that TH immuno- 


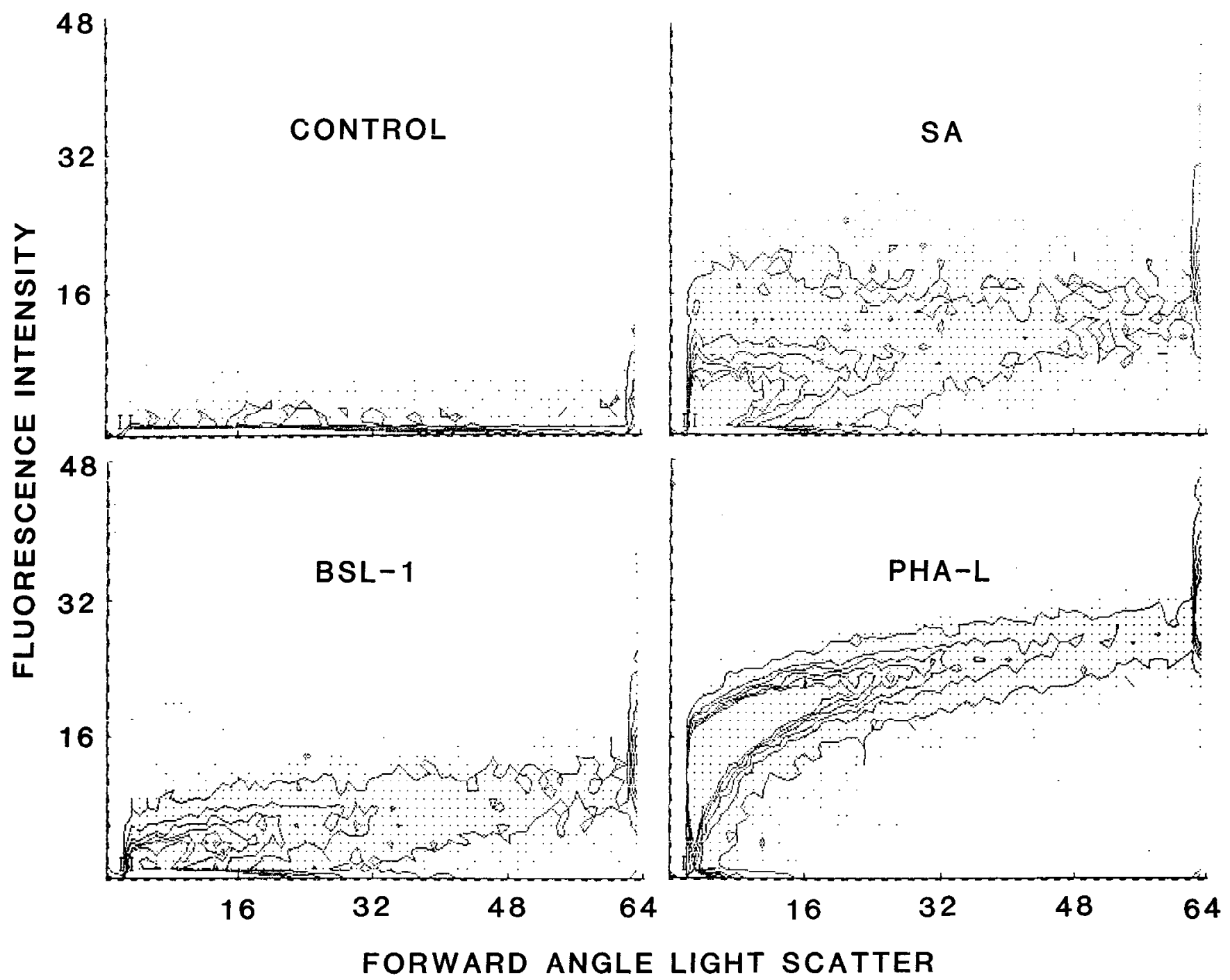

Figure 6. Dual parameter plots of FALS and fluorescence illustrating labeling of subpopulations of synaptosomes by several FITC-conjugated plant lections. BSL-1, Bandeiraea simplicifolia I; $S A$, soybean agglutinin; $P H A-L$, Phaseolus vulgaris leucoagglutinin.

reactivity could be detected in synaptosomes collected onto membrane filters by FACS. The spots shown in Figure 7 contain defined numbers of particles from the synaptosomal fraction that were probed with a monoclonal antibody to TH (Kapatos and Kuhn, in preparation) and an alkaline phosphataseconjugated secondary antibody. The amount of TH immunoreactivity in these synaptosomal spots was proportional to the number of particles collected (Fig. 8), as would bc cxpccted if $\mathrm{TH}$-containing synaptosomes are randomly distributed in control samples.

Using this method, the amount of TH immunoreactivity in equal numbers of unlabeled and labeled synaptosomes was determined for each lectin in Table 1. For most lectins, similar amounts of TH immunoreactivity were observed in labeled and unlabeled subpopulations. There were, however, some exceptions. For example, synaptosomes recognized by SA contained approximately 3 times as much $\mathrm{TH}$ as synaptosomes not recognized by SA (Fig. 9). In no case, however, did a lectin exclusively label either dopaminergic or nondopaminergic synaptosomes.

\section{Discussion}

To our knowledge, these studies represent the first application of flow cytometry to the analysis of mammalian nerve terminals (synaptosomes). The purpose of this work was to illustrate the usefulness of FACS in characterizing a heterogeneous population of particles such as the synaptosomal fraction and in identifying previously unknown constituents (e.g., astrocyte-derived particles). Furthermore, these experiments demonstrate that subpopulations of synaptosomes can be detected by FACS based on differences in physiological responsiveness, cell surface molecules, and intracellular components. Once separated by FACS, subpopulations of synaptosomes defined by any of the above criteria (e.g., recognition by specific lectins) can be further characterized using Western blot techniques.

The composition of the fractions generated in the course of synaptosome preparation has been well characterized using techniques such as electron microscopy and marker enzyme assays (Gray and Whittaker, 1962; Hajós, 1975; Booth and 


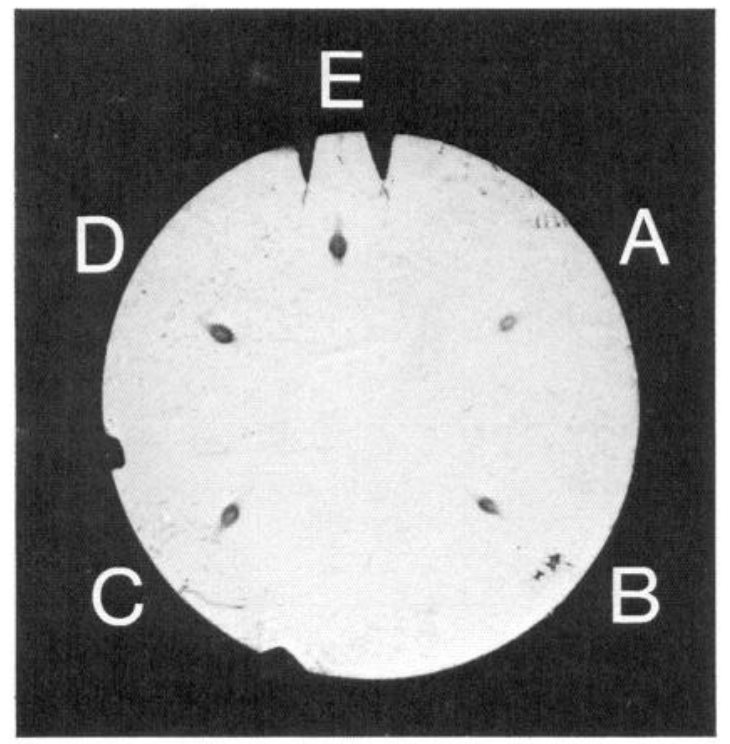

Figure 7. Western blot analysis of defined numbers of striatal synaptosomes collected by FACS. Tyrosine hydroxylase was detected using monoclonal antibody LNC 1 and alkaline phosphatase-conjugated secondary antibody. Synaptosomal spots contain the following numbers of particles: $A, 2 \times 10^{5} ; B, 4 \times 10^{5} ; C, 6 \times 10^{5} ; D, 8 \times 10^{5}$; and $E, 1$ $\times 10^{6}$.

Clark, 1978; Mena et al., 1980; Dagani et al., 1985; Dunkley et al., 1986). It was therefore important to establish that flow cytometric methods produce results consistent with those obtained using conventional methods of analysis. For example, light scatter analysis indicated that particles in the synaptosomal fraction range from several tenths of a micron to several microns in diameter, while particles in the mitochondrial fraction are generally smaller. This is consistent with estimates of synaptosomal and mitochondrial diameters obtained using electron microscopy (Gray and Whittaker, 1962; Dunkley et al., 1986). Furthermore, light scatter analysis could be used to demonstrate the well-documented sensitivity of synaptosomes to hypotonic lysis (Bradford, 1969).

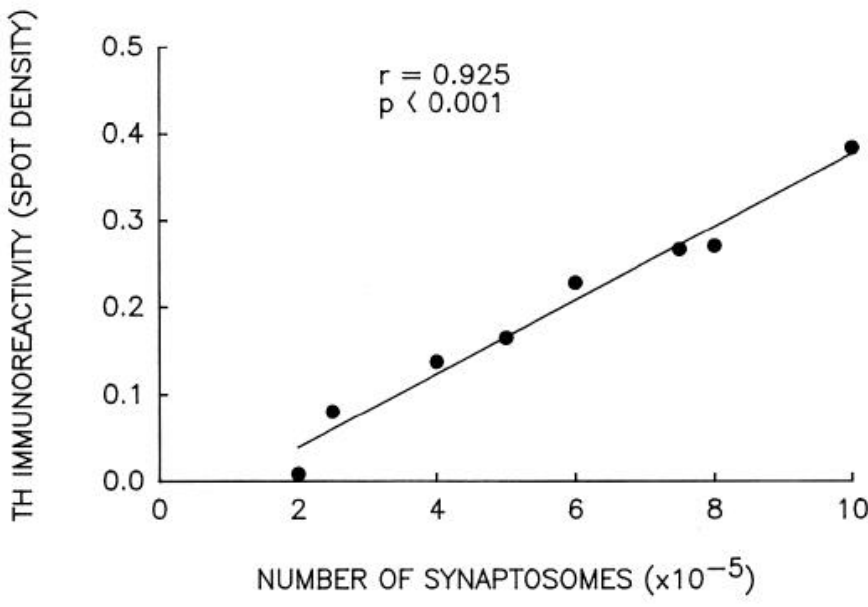

Figure 8. Relationship between the number of synaptosomes collected by FACS and TH immunoreactivity as evaluated by scanning densitometry. Data were obtained by scanning filters similar to the one shown in Figure 7.

Light scatter analysis, however, is not sufficient to discriminate between synaptosomes and other particles. For example, there is considerable overlap between the FALS signals generated by the synaptosomal and mitochondrial fractions. Synaptosomes could be distinguished more definitively using monoclonal antibody A2B5, which recognizes a polysialoganglioside (GQ) present on the surface of most or all neurons (Eisenbarth et al., 1979) but not on mature astrocytes or oligodendrocytes (Berg and Schachner, 1982; Schnitzer and Schachner, 1982; Abney et al., 1983). FACS analysis of antibody binding indicated that $83.9 \pm 1.7 \%$ of the synaptosomal fraction was specifically labeled by A2B5. This is probably an overestimate of the percentage of intact synaptosomes in the preparation, however, since A2B5 should also recognize membrane fragments or damaged synaptosomes containing this neuronal marker.

A novel finding is that anti-GFAP monoclonal antibodies recognize $7.5 \pm 1.4 \%$ of the synaptosomal fraction, suggesting that portions of astrocytes pinch off during tissue homogenization and form resealed vesicles that fractionate with synap-

Table 1. FITC-conjugated plant lectins recognize subpopulations of striatal synaptosomes

\begin{tabular}{|c|c|c|}
\hline Lectin & Carbohydrate specificity & $\begin{array}{l}\% \\
\text { Synaptosomes } \\
\text { bound }\end{array}$ \\
\hline Bandeiraea simplicifolia I & $\alpha$-N-Acetylgalactosamine $/ \alpha$-galactose & 33.1 \\
\hline Concanavalin A & $\alpha$-Mannose & 98.6 \\
\hline Dilichos biflorus agglutinin & $N$-Acetylgalactosamine & 63.6 \\
\hline Lens culinaris agglutinin & $\alpha$-Mannose & 97.6 \\
\hline Peanut agglutinin & Galactosyl $(\beta-1,3) N$-acetylgalactosamine & 78.0 \\
\hline Phaseolus vulgaris agglutinin & Leucoagglutinin & 96.1 \\
\hline Pisum sativum agglutinin & $\alpha$-Mannose & 97.7 \\
\hline Ricinus communis agglutinin I & Galactose/ $N$-acetylgalactosamine & 98.0 \\
\hline Sophora japonica agglutinin & $\mathrm{N}$-Acetylgalactosamine/galactose & 5.6 \\
\hline Soybean agglutinin & $\mathrm{N}$-Acetylgalactosamine/galactose & 50.1 \\
\hline Ulex europaeus agglutinin & $\alpha$-Fucose & 18.1 \\
\hline Wheat germ agglutinin & $N$-Acetylglycosamine & 97.7 \\
\hline
\end{tabular}

Synaptosomes were incubated for $30 \mathrm{~min}$ at a final lectin concentration of $2 \mu \mathrm{g} / \mathrm{ml}$. This concentration was selected because it has been shown to be well below the level which produces lectin receptor saturation and cell agglutination (Malin-Berdel et al., 1984), which would interfere with flow cytometric measurements. In fact, synaptosomes displayed no changes in light scattering properties after labeling with plant lectins (data not shown). 


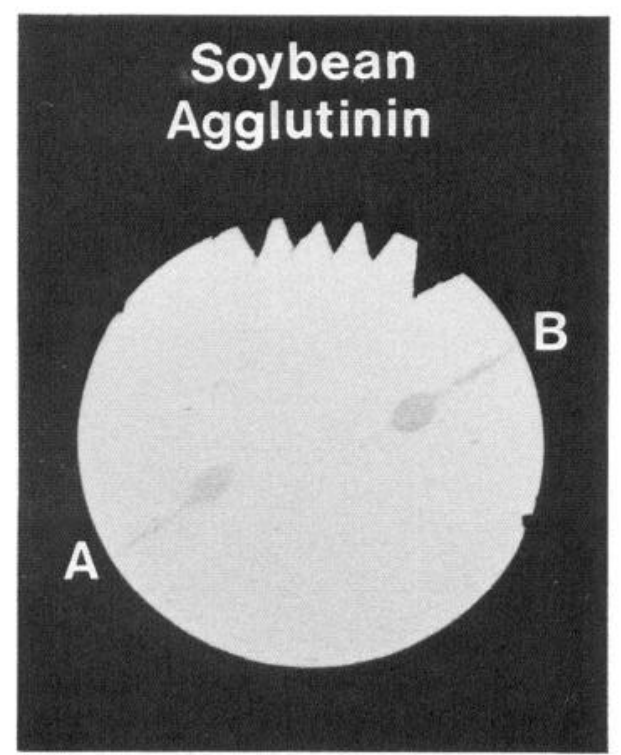

Figure 9. Western blot analysis of sorted striatal synaptosomes illustrating preferential localization of tyrosine hydroxylase in synaptosomes with soybean agglutinin (SA) binding sites ( $A=500,000$ synaptosomes not labeled by SA; $B=500,000$ synaptosomes labeled by SA).

tosomes. This might explain, in part, the presence of membraneenclosed bodies lacking synaptic vesicles and other synaptic specializations in electron micrographs of synaptosome-enriched fractions (Gray and Whittaker, 1962; Booth and Clark, 1978; Mena et al., 1980; Dunkley et al., 1986). The existence of glia-derived particles, or gliosomes, in the synaptosomal fraction has been suggested by previous studies showing that vesicles derived from either cultured glia cells or the astrocyte-derived C-6 glioma cell line band in the same region as synaptosomes during density gradient centrifugation (Cotman et al., 1971; Henn et al., 1976). Furthermore, synaptosomal fractions are known to contain contaminants with a high specific activity of $2^{\prime}, 3^{\prime}$-cyclic nucleotide $3^{\prime}$-phosphohydrolase, an enzyme that is enriched in the membranes of C-6 glioma cells (see Mena et al., 1980). The present results, however, provide the first direct demonstration of the presence of gliosomes in the synaptosomal fraction, as well as a method for quantifying gliosome contamination.

An alternative means of distinguishing synaptosomes from other particles was based on the fact that synaptosomes are known to possess a significant membrane potential (estimates range from -45 to $-87 \mathrm{mV}$; see Blaustein and Goldring, 1975; Deutsch and Rafalowska, 1979; Hansson et al., 1980; Scott and Nicholls, 1980; Heinonen et al., 1985). In the present study, the fluorescent voltage-sensitive dye Di-O- $\mathrm{C}_{5}(3)$ was used to detect particles with a membrane potential. Because of its cationic nature, this dye partitions into negatively charged compartments. While other investigators have used voltage-sensitive dyes to measure the membrane potential of synaptosomes and synaptoneurosomes (Blaustein and Goldring, 1975; Kamino et al., 1978; Aiuchi et al., 1985; Heinonen et al., 1985; Åkerman et al., 1987), FACS analysis of dye distribution offers the important advantage of discriminating between responsive and nonresponsive populations. Our results indicate that $82.6 \pm$ $1.2 \%$ of the synaptosomal fraction possess a significant membrane potential. Furthermore, most of these particles depolarize in response to $55 \mathrm{~mm} \mathrm{KCl}$ or $75 \mu \mathrm{M}$ veratridine.
These findings suggest that intact synaptosomes can be identified by FACS and subjected to flow cytometric analysis without loss of physiological responsiveness. In preliminary studies, subpopulations of the synaptosomal fraction exhibited depolarizing and hyperpolarizing responses, respectively, following incubation with the excitatory transmitter glutamic acid or the DA agonist apomorphine (Wolf and Kapatos, in press). This suggests that occupation of receptors on nerve terminals can modulate terminal membrane potential, as has been concluded previously from electrophysiological studies of terminal excitability in intact rats (see Tepper et al., 1985, for a review).

It seems likely that those particles in the synaptosomal fraction that possess a substantial membrane potential are intact synaptosomes rather than free mitochondria. While there have been no measurements of the membrane potential of free mitochondria under the precise experimental conditions used in our studies, a considerable amount of data suggests that the mitochondrial membrane potential will be dissipated under these conditions. According to the chemiosmotic hypothesis of oxidative phosphorylation, the mitochondrial membrane potential is due to the extrusion of hydrogen ions from the matrix as a result of the activity of the respiratory chain (Mitchell, 1966). For coupled mitochondria supplied with substrate or ATP, a membrane potential in the range of -130 to $-190 \mathrm{mV}$ has been reported (Mitchell and Moyle, 1969; Nicholls, 1974; Åkerman and Wikström, 1976; Åkerman, 1979; Deutsch et al., 1979; Scott and Nicholls, 1980). However, free mitochondria do not respire when incubated in glucose-containing Ringer's solution because a suitable substrate is lacking (Bradford, 1969). Furthermore, high external calcium concentrations ( $1 \mathrm{~mm}$ in our studies) in the presence of inorganic phosphate are lethal to mitochondria and result in a collapse of the mitochondrial membrane potential (Nicholls and Crompton, 1980). These observations are consistent with the present finding that most particles in the mitochondrial fraction do not take up significant amounts of Di-O-C $\mathrm{C}_{5}(3)$.

Voltage-sensitive dye experiments would not be expected to distinguish between synaptosomes and gliosomes since glial cells have resting potentials in the same range as neurons (Kuffler, 1967). Recently, cultured astrocytes have been shown to possess voltage-dependent sodium, potassium, and calcium channels (Bowman et al., 1984; Bevan and Raff, 1985; Barres et al., 1988). Gliosomes might therefore be expected to take up voltage-sensitive dyes and to exhibit changes in dye distribution in response to elevated potassium or veratridine. Thus, the $82.6 \pm 1.2 \%$ of the synaptosomal fraction shown to possess a membrane potential in voltage-sensitive dye experiments may contain both synaptosomes and gliosomes. By summing the percentages of particles recognized by A2B5 and anti-GFAP monoclonal antibodies, it can be estimated that particles expressing glia- or neuron-specific markers constitute approximately $90 \%$ of the synaptosomal fraction. This is greater than the percentage of particles that appear to possess a membrane potential. The difference probably represents damaged synaptosomes or gliosomes. The remaining $10 \%$ of the synaptosomal fraction can presumably be identified as mitochondria or membrane fragments containing neither GFAP nor GQ ganglioside. These results are essentially consistent with previous estimates, although direct comparisons are difficult because of the different methods used by various investigators to calculate synaptosomal purity (see Hajós, 1975; Mena et al., 1980; Dagani et al., 1985; Dunkley et al., 1986). 
Plant lectins are polypeptides that bind with high affinity to specific sugars and have been used extensively to study differences in the cell surface glycoconjugates expressed by mammalian neurons and other cell types (for reviews, see Nicholson, 1974; Goldstein and Hayes, 1978). In several recent studies, How cytometric methods have been used to study lectin binding to dissociated cells (Reimann et al., 1984; St. John et al., 1986; Notter and Leary, 1987; Saunders ct al., 1987). Our results demonstrate that subpopulations of synaptosomes can be defined using an array of fluorescein-conjugated lectins with different carbohydrate binding specificities, suggesting that nerve terminals in the adult rat brain differ significantly in their glycoconjugate composition. This may have important implications for synapse formation and maintenance.

Additional studies were conducted to determine the distribution of dopaminergic synaptosomes in subpopulations of synaptosomes recognized by different plant lectins. The purpose of these experiments was 2-fold. First, they were designed to illustrate that subpopulations of intact synaptosomes detected by FACS can be separated, collected, permeabilized, and probed for an antigen of interest. Second, if dopaminergic terminals proved to be unique in their cell surface glycoconjugates, flow cytometric isolation of DA terminals would be possible using an appropriate FITC-conjugated lectin.

Preliminary experiments established that TH-containing synaptosomes could be detected in samples of FACS-isolated synaptosomes by probing with a monoclonal antibody directed against $\mathrm{TH}$ and an alkaline phosphatase-conjugated secondary antibody. Since the striatum is essentially devoid of norepinephrine- or epinephrine-containing nerve terminals (Swanson and Hartman, 1975), synaptosomes that contain TH can bc identified as dopaminergic. The intensity of the synaptosomal spots, determined using a scanning densitometer, was highly correlated with the number of particles collected by the cell sorter. These data establish that this approach can be used to quantify the relative number of dopaminergic synaptosomes, or the relative content of any other antigen, in unknown samples.

For each of the lectins, equal numbers of synaptosomes that were either labeled or not labeled by a particular lectin were collected onto membrane filters by FACS and immunoprobed for TH as described above. While TH was enriched in several subpopulations of synaptosomes defined by lectin binding, none of the lectins labeled either dopaminergic or nondopaminergic synaptosomes exclusively. Thus, while this approach provides a means of characterizing glycoconjugates on subpopulations of nerve terminals, it does not provide a selective probe with which to identify and isolate intact DA nerve terminals (see Wolf and Kapatos, 1989).

In conclusion, our results demonstrate that subpopulations of intact synaptosomes can be analyzed and separated by FACS. Many types of additional analysis are possible given the appropriate fluorescent probes. For example, flow cytometric methods are well suited to receptor binding studies (for review, see Bohn, 1980) and have been used to study the cellular binding of a number of fluorescently labeled ligands, including a chemotactic peptide, estrogens, and luteinizing hormone-releasing hormone (Sklar and Finney, 1982; Kute et al., 1983; MacInnes et al., 1983; Oxenhandler et al., 1984; Benz et al., 1985). Since 2 or more fluorescence signals can be analyzed simultaneously, it should be possible to characterize and sort nerve terminals based on the coincidence of several cell surface and/or intracellular molecules. These might include neurotransmitters, enzymes, ion channels, receptors, and transporters. In addition to detecting cellular constituents, FACS can be used to monitor physiological responses such as changes in membrane potential (see above) or intracellular calcium levels (Lazzari et al., 1986; Rabinovitch et al., 1986; Chused et al., 1987; Kapatos and Wolf, 1988; Wolf and Kapatos, 1988) and to separate subpopulations based on differences in responsiveness to neurotransmitters or other cellular messengers (Schieren and MacDermott, in press). Flow cytometry may therefore provide a novel means of studying the function of chemically identified nerve terminals.

\section{References}

Abney, E. R., B. P. Williams, and M. C. Raff (1983) Tracing the development of oligodendrocytes from precursor cells using monoclonal antibodies, fluorescence-activated cell sorting, and cell culture. Dev. Biol. 100: 166-171.

Aiuchi, T., M. Matsunaga, K. Nakaya, and Y. Nakamura (1985) Effects of probes of membrane potential on metabolism in synaptosomes. Biochim. Biophys. Acta 843: 20-24.

Akerman, K. E. O. (1979) Qualitative measurements of the mitochondrial membrane potential in situ in Ehrlich ascites tumour cells using the safranine method. Biochim. Biophys. Acta 546: 341-347.

Åkerman, K. E. O., and M. K. F. Wikström (1976) Safranine as a probe of the mitochondrial membrane potential. FEBS Lett. 68: 191197.

Åkerman, K. E. O., I. G. Scott, J. E. Heikkila, and E. Heinonen (1987) Ionic dependence of membrane potential and glutamate receptorlinked responses in synaptoneurosomes as measured with a cyanine dye, DiS-C $-(5)$. J. Neurochem. 48: 552-559.

Barres, B. A., L. L. Y. Chun, and D. P. Corey (1988) Ion channel expression by white matter glia: I. Type 2 astrocytes and oligodendrocytes. Glia 1: 10-30.

Bashford, C. L. (1981) The measurcment of membrane potential using optical indicators. Biosci. Rep. 1: 183-196.

Benson, M. C., D. C. McDougal, and D. S. Coffey (1984) The application of perpendicular and forward light scatter to assess nuclear and cellular morphology. Cytometry 5: 515-522.

Benz, C., I. Wiznitzer, and S. H. Lee (1985) Flow cytometric analysis of fluorescein-conjugated estradiol (E-BSA-FITC) binding in breast cancer suspensions. Cytometry 6: 260-267.

Berg, G. J., and M. Schachner (1982) Electron-microscopic localization of A2B5 cell surface antigen in monolayer cultures of murine cerebellum and retina. Cell Tissue Res. 224: 637-645.

Bevan, S., and M. Raff (1985) Voltage-dependent potassium currents in cultured astrocytes. Nature $315: 229-232$.

Bignami, A., D. Dahl, and D. C. Rueger (1980) Glial fibrillary acidic protein (GFA) in normal neural cells and in pathological conditions. Adv. Cell. Neurobiol. 1: 285-310.

Blake, M. S., K. H. Johnston, G. J. Russell-Jones, and E. C. Gotschlich (1984) A rapid, sensitive method for detection of alkaline phosphatase-conjugated anti-antibody on western blots. Anal. Bicchem. 136: $175-179$.

Blaustein, M. P., and J. M. Goldring (1975) Membrane potentials in pinched-off presynaptic nerve terminals monitored with fluorescent probes: Evidence that synaptosomes have potassium diffusion potentials. J. Physiol. (Lond.) 247: 589-615.

Bohn, B. (1980) Flow cytometry: A novel approach for the quantitative analysis of receptor-ligand interactions on surfaces of living cells. Mol. Cell. Endocrinol. 20: 1-15.

Booth, R. F. G., and J. B. Clark (1978) A rapid method for the preparation of relatively pure metabolically competent synaptosomes from rat brain. Biochem. J. 176: 365-370.

Bowman, C. L., H. K. Kimelberg, M. V. Frangakis, Y. Berwald-Netter, and C. Edwards (1984) Astrocytes in primary culture have chemically activated sodium channels. J. Neurosci. 4: 1527-1534.

Bradford, H. F. (1969) Respiration in vitro of synaptosomes from mammalian cerebral cortex. J. Neurochem. 16: 675-684.

Chused, T. M., H. A. Wilson, D. Greenblatt, Y. Ishida, L. J. Edison, R. Y. Tsien, and F. D. Finkelman (1987) Flow cytometric analysis of murine splenic B lymphocyte cytosolic free calcium response to anti-IgM and anti-IgD. Cytometry $8: 396-404$. 
Cohen, L. B., and B. M. Salzberg (1978) Optical measurement of membrane potential. Rev. Physiol. Biochem. Pharmacol. 83: 35-88.

Cotman, C., H. Herschman, and D. Taylor (1971) Cellular subfractionation of cultured glial cells. J. Neurobiol. 2: 169-180

Dagani, F., F. Zanada, F. Marzatico, and G. Benzi (1985) Free mitochondria and synaptosomes from single rat forebrain. A comparison between two known subfractionation techniques. J. Neurochem. 45: 653-656.

Deutsch, C., and U. Rafalowska (1979) Transmembrane electrical potential measurements in rat brain synaptosomes. FEBS Lett. 108: 274-278.

Deutsch, C., M. Erecińska, R. Werrlein, and I. A. Silver (1979) Cellular energy metabolism, trans-plasma and trans-mitochondrial membrane potentials, and $\mathrm{pH}$ gradients in mouse neuroblastoma. Proc. Natl. Acad. Sci. USA 76: 2175-2179.

di Porzio, U., G. Rougon, E. A. Novotny, and J. L. Barker (1987) Dopaminergic neurons from embryonic mouse mesencephalon are enriched in culture through immunoreaction with monoclonal antibody to neural specific protein 4 and flow cytometry. Proc. Natl. Acad. Sci. USA 84: 7334-7338.

Dunkley, P. R., P. E. Jarvie, J. W. Heath, G. J. Kidd, and J. A. P. Rostas (1986) A rapid method for isolation of synaptosomes on percoll gradients. Brain Res. 372: 115-129.

Eisenbarth, G. S., F. S. Walsh, and M. Nirenberg (1979) Monoclonal antibody to a plasma membrane antigen of neurons. Proc. Natl. Acad. Sci. USA 76: 4913-4917.

Goldstein, I. J., and C. E. Hayes (1978) The lectins: Carbohydratebinding proteins of plants and animals. Adv. Chem. Biochem. 35: $127-340$.

Gray, E. G., and V. P. Whittaker (1962) The isolation of nerve endings from brain: An electron-microscopic study of cell fragments derived by homogenization and centrifugation. J. Anat. 96: 79-88.

Haas, R. H., G. Thompson, B. Morris, K. Conright, and T. Andrews (1988) Pyruvate dehydrogenase activity in osmotically shocked rat brain mitochondria: Stimulation by oxaloacetate. J. Neurochem. 50 : 673-680.

Hajós, F. (1975) An improved method for the preparation of synaptosomal fractions in high purity. Brain Res. 93: 485-489.

Hansson, E., I. Jacobson, R. Venema, and A. Sellstrom (1980) Measurement of the membrane potential of isolated nerve terminals by the lipophilic cation $\left[{ }^{3} \mathrm{H}\right]$ triphenylmethylphosphonium bromide. $\mathbf{J}$. Neurosci. 34: 569-573.

Hatfield, J. M., and W. C. Hymer (1986a) Flow cytometric analysis and sorting of live male rat anterior pituitary cell types by forward angle and perpendicular light scatter. Endocrinology 119:2670-2682.

Hatfield, J. M., and W. C. Hymer (1986b) Flow cytometric analysis and sorting of live female rat anterior pituitary cell types by forward angle and perpendicular light scatter: Effect of $17 \beta$-estradiol. Endocrinology 119: 2683-2694.

Heinonen, E., K. E. O. Åkerman, K. Kaila, and I. G. Scott (1985) Dependence of cytoplasmic calcium transients on the membrane potential in isolated nerve endings of the guinea pig. Biochim. Biophys. Acta 815: 203-208.

Henn, F. A., D. J. Anderson, and D. G. Rustad (1976) Glial contamination of synaptosomal fractions. Brain Res. 101: 341-344.

Hickman, J. A., O. C. Blair, A. L. Stepanowski, and A. C. Sartorelli (1984) Calcium-induced heterogeneous changes in membrane potential detected by flow cytofluorimetry. Biochim. Biophys. Acta 778 457-462.

Hökfelt, T. (1968) In vitro studies on central and peripheral monoamine neurons at the ultrastructural level. Z. Zellforsch. 91: 1-74

Hökfelt, T., and U. Ungerstedt (1969) Electron and fluorescence microscopical studies on the nucleus caudatus putamen of the rat after unilateral lesions of ascending nigro-neostriatal dopamine neurons. Acta Physiol. Scand. 76: 415-426.

Iversen, L. L., and F. E. Schon (1973) The use of autoradiographic techniques for the identification and mapping of transmitter-specific neurones in CNS. In New Concepts in Neurotransmitter Regulation, A. J. Mandell, ed., pp. 153-193, Plenum, New York.

Jahn, R., W. Schiebler, and P. Greengard (1984) A quantitative dotimmunobinding assay for proteins using nitrocellulose membrane filters. Proc. Natl. Acad. Sci. USA 81: 1684-1687.

Jenssen, H. L., K. Redmann, and E. Mix (1986) Flow cytometric estimation of transmembrane potential of macrophages - A comparison with microelectrode measurements. Cytometry 7: 339-346.

Johnson, D. A., J. W. Gautsch, J. R. Sportsman, and J. H. Elder (1984)
Improved technique utilizing nonfat dried milk for analysis of proteins and nucleic acids transferred to nitrocellulose. Gene Anal. Technol. $1:$ 3-8.

Jones, D. H., and Matus, A. I. (1974) Isolation of synaptic plasma membrane from brain by combined flotation-sedimentation density gradient centrifugation. Biochim. Biophys. Acta 356: 276-287.

Kamino, K., and A. Inouye (1978) Evidence for membrane potential changes in isolated synaptic membrane ghosts monitored with a merocyanine dye. Jpn. J. Physiol. 28: 225-237.

Kapatos, G., and M. E. Wolf (1988) Flow cylometric analysis of calcium levels in PC1 2 cells and embryonic mesencephalic neurons. Soc. Neurosci. Abstr. 14: 135.

Kerker, M., H. Chew, P. J. McNulty, J. P. Kratohvil, D. D. Cooke, M. Sculley, and M.-P. Lee (1979) Light scattering and fluorescence by small particles having internal structure. J. Histochem. Cytochem. 27: $250-263$

Kruth, H. S. (1982) Flow cytometry: Rapid biochemical analysis of single cells. Anal. Biochem. 125: 225-242.

Kuffler, S. W. (1967) Neurological cells: Physiological properties and a potassium mediated effect of neuronal activity on the glial membrane. Proc. R. Soc. London [Biol.] 168: 1-21

Kute, T. E., C. Linville, and G. Barrows (1983) Cytofluorometric analysis for estrogen receptors using fluorescent estrogen probes. Cytometry 4: 132-140.

Lazzari, K. G., P. J. Proto, and E. R. Simons (1986) Simultaneous measurement of stimulus-induced changes in cytoplasmic $\mathrm{Ca}^{2+}$ and in membrane potential of human neutrophils. J. Biol. Chem. 261: 9710-9713.

Ledbetter, J. A., and L. A. Herzenberg (1979) Zenogeneic monoclonal antibodies to mouse differentiation antigens. Immunol. Rev. 47: 6390.

Loken, M. R., and A. M. Stall (1982) Flow cytometry as an analytical and preparative tool in immunology. J. Immunol. Methods 50: R85R112.

MacInnes, D. G., D. K. Green, A. Harmar, E. G. Nairn, and G. Fink (1983) Neuropeptide-receptor interactions studied with the aid of fluorescence-activated cell sorting and video intensification microscopy. J. Neurosci. Methods 7: 309-316.

Malin-Berdel, J., G. Valet, E. Thiel, J. A. Forester, and L. Gurtler (1984) Flow cytometric analysis of the binding of eleven lectins to human T- and B-cells and to human T- and B-cell lines. Cytometry 5: 204209.

Mandler, R. N., A. E. Schaffner, E. A. Novotny, G. D. Lange, and J. L. Barker (1988) Flow cytometric analysis of membrane potential in embryonic rat spinal cord cells. J. Neurosci. Methods 22: 203-213.

Mena, E. E., C. A. Hoeser, and B. W. Moore (1980) An improved method of preparing rat brain synaptic membranes. Elimination of a contaminating membrane containing $2^{\prime}, 3^{\prime}$-cyclic nucleotide $3^{\prime}$-phosphohydrolase activity. Brain Res. 188: 207-231.

Mitchell, P. (1966) Coupling of phosphorylation to electron and hydrogen transfer by a chemi-osmotic type of mechanism. Nature 191: 144-148.

Mitchell, P., and J. Moyle (1969) Estimation of membrane potential and $\mathrm{pH}$ difference across the cristae membrane of rat liver mitochondria. Eur. J. Biochem. 7: 471-484.

Moktari, S., H. Feracci, J.-P. Gorvel, Z. Mishal, A. Rigal, and S. Maroux (1986) Subcellular fractionation and subcellular localization of aminopeptidase $\mathrm{N}$ in the rabbit enterocytes. J. Membr. Biol. 89: 53-63.

Moskal, J. R., and A. E. Schaffner (1986) Monoclonal antibodies to the dentate gyrus: Immunocytochemical characterization and flow cytometric analysis of hippocampal neurons bearing a unique cellsurface antigen. J. Neurosci. 6: 2045-2053.

Mullaney, P. F., M. A. Van Dilla, J. R. Coulter, and P. N. Dean (1969) Cell sizing: A light scattering photometer for rapid volume determination. Rev. Sci. Instrum. 40: 1029-1032.

Nicholls, D. G. (1974) The influence of respiration and ATP hydrolysis on the proton-electrochemical gradient across the inner membrane of rat-liver mitochondria as determined by ion distribution. Eur. J. Biochem. 50: 305-315.

Nicholls, D. G., and M. Crompton (1980) Mitochondrial calcium transport. FEBS Lett. 111: 261-268.

Nicholson, G. L. (1974) The interactions of lectins with animal cell surfaces. Int. Rev. Cytol. 39: 89-190.

Notter, M. F. D., and J. F. Leary (1987) Surface glycoproteins of differentiating neuroblastoma cells analyzed by lectin binding and flow cytometry. Cytometry $8: 518-525$. 
O'Brien, R. J., and G. D. Fischbach (1986) Isolation of embryonic chick motoneurons and their survival in vitro. J. Neurosci. 6: 32653274.

Oxenhandler, R. W., R. McCune, A. Subtelney, C. Truelove, and H. W. Tryer (1984) Flow cytometric determination of estrogen receptors in intact cells. Cancer Res. 44: 2516-2523.

Peterson, G. L. (1977) A simplification of the protein assay method of Lowry et al. which is more generally applicable. Anal. Biochem. 83: 346-356.

Rabinovitch, P. S., C. H. June, A. Grossmann, and J. A. Ledbetter (1986) Heterogeneity among $T$ cells in intracellular free calcium responses after mitogen stimulation with PHA or anti-CD3. Simultaneous use of INDO- 1 and immunofluorescence with flow cytometry. J. Immunol. 137: 952-961.

Reimann, J., D. Ehman, and R. G. Miller (1984) Differential binding of lectins to lymphopoietic and myelopoietic cells in murine marrow as revealed by flow cytometry. Cytometry 5: 194-203.

Saunders, G. C., J. A. Steinkamp, and B. E. Lehnert (1987) Flow cytometric analyses of lectin binding to rat alveolar macrophages. Cytometry 8: 602-611.

Schaffner, A. E., P. A. St. John, and J. L. Barker (1987) Fluorescenceactivated cell sorting of embryonic mouse and rat motoneurons and their long-term survival in vitro. J. Neurosci. 7: 3088-3104.

Schieren, I., and A. MacDermott (in press) Flow cytometric identification and purification of cells by ligand-induced changes in intracellular calcium. J. Neurosci. Methods.

Schnitzer, J., and M. Schachner (1982) Cell type specificity of a neural cell surface antigen recognized by the monoclonal antibody A2B5. Cell Tissue Res. 224: 625-636.

Scott, I. D., and D. G. Nicholls (1980) Energy transduction in intact synaptosomes. Influence of plasma-membrane depolarization on the respiration and membrane potential of internal mitochondria determined in situ. Biochem. J. 186: 21-33.

Seligman, B. E., and J. I. Gallin (1983) Comparison of indirect probes of membrane potential utilized in studies of human neutrophils. J. Cell. Physiol. 115: 105-115.

Seligman, B., T. M. Chused, and J. I. Gallin (1981) Human neutrophil heterogeneity identified using flow microfluorometry to monitor membrane potential. J. Clin. Invest. 68: 1125-1131.

Shapiro, H. M., P. J. Natale, and L. A. Kamentsky (1979) Estimation of membrane potentials of individual lymphocytes by flow cytometry. Proc. Natl. Acad. Sci. USA 80: 7178-7182.

Sklar, L. A., and D. A. Finney (1982) Analysis of ligand-receptor interactions with the fluorescence activated cell sorter. Cytometry 3 : $161-165$.

St. John, P. A., W. M. Kell, J. S. Mazzetta, G. D. Lange, and J. L. Barker (1986) Analysis and isolation of embryonic mammalian neurons by fluorescence-activated cell sorting. J. Neurosci. 6: 1492-1512.

Sullivan, R., D. A. Melnick, H. L. Malech, T. Mesulam, E. R. Simons, K. G. Lazzari, P. J. Proto, A.-S. Gadenne, J. L. Leavitt, and J. D. Griffin (1987) The effects of phorbol myristate acetate and chemotactic peptide on transmembrane potentials and cytosolic free calcium in mature granulocytes evolve sequentially as the cells differentiate. J. Biol. Chem. 262: 1274-1281.

Swanson, L. W., and B. K. Hartman (1975) The central adrenergic system. An immunofluorescence study of the location of cell bodies and their efferent connections in the rat utilizing dopamine- $\beta$-hydroxylase as a marker. J. Comp. Neurol. 163:467-505.

Tatham, P. E. R., and P. J. Delves (1984) Flow cytometric detection of membrane potential changes in murine lymphocytes induccd by concanavalin A. J. Clin. Immunol. 221: 137-146.

Tepper, J. M., P. M. Groves, and S. J. Young (1985) The neuropharmacology of the autoinhibition of monoamine release. Trends Pharmacol. Sci. 6: 251-256.

Waggoner, A. S. (1979) Dye indicators of membrane potential. Annu. Rev. Biophys. Bioeng. 8: 47-68.

Wilson, H. A., and T. M. Chused (1985) Lymphocyte membrane potential and $\mathrm{Ca}^{2+}$-sensitive potassium channels described by oxonol dye fluorescence measurements. J. Cell. Physiol. 125: 72-81.

Wolf, M. E., and G. Kapatos (1988) Flow cytometric analysis of calcium levels in rat striatal synaptosomes. Soc. Neurosci. Abstr. 14: 135.

Wolf, M. E., and G. Kapatos (1989) Flow cytometric analysis and isolation of permeabilized dopamine nerve terminals from rat striatum. J. Neurosci. 9: 106-114.

Wolf, M. E., and G. Kapatos (in press) Neurobiological applications of flow cytometry: Characterization of a striatal synaptosomal fraction and isolation of dopaminergic nerve terminals. In Perspectives in the Neurobiology of Dopamine, D. Clark, M. P. Galloway, and S. Hjorth, eds., Plenum, London. 